\title{
Identification of stress-responsive transcription factors with protein-bound Escherichia coli genomic DNA libraries
}

\author{
Xianqiang $\mathrm{Li}^{1^{*}}$, Xin Jiang ${ }^{1}$, Meiying $\mathrm{Xu}^{{ }^{1 *}}$, Yun Fang ${ }^{1}$, Yan Wang ${ }^{2}$, Guoping Sun ${ }^{1}$ and Jun Guo ${ }^{1}$
}

\begin{abstract}
Bacteria promoters along with operators are crucial elements in the control of gene expression in microbes in response to environmental stress changes. A genome-wide promoter DNA regulatory library is in demand to be developed for a microbe reporter method to monitor the existence of any given environmental stress substance. In this study, we utilized Escherichia coli (E. coli) as a model system for the preparation of both cell lysates and genomic DNA fragments. Through enriching protein-bound DNA fragments to construct luciferase reporter libraries, we found that, of 280 clones collected and sequenced, 131 clones contained either the promoter-35 and -10 conservative sequences and/or an operator transcription factor binding sites (TFBS) region. To demonstrate the functionality of the identified clones, five of 131 clones containing LexA binding sequence have been demonstrated to be induced in response to mitomycin $C$ treatment. To evaluate our libraries as a functional screening library, 80 randomly picked up clones were cultured and treated with and without MMC, where two clones were shown to have greater than twofold induction. In addition, two arsenite-responsive clones were identified from 90 clones, one having the well-known ArsR and another having the osmotically inducible lipoprotein (OsmE1). The newly discovered osmE1 has been quantitatively validated to be induced by arsenite treatment with real-time PCR in a dose response and time course manner. This enriching protein-bound DNA luciferase reporter libraries and functional screening facilitate the identification of stress-responsive transcriptional factors in microbes. We developed functional libraries containing E. coli genomicwide protein-bound DNA as enhancers/operators to regulate downstream luciferase in response to stress.
\end{abstract}

Keywords: Genomic DNA libraries, Luciferase assay, Transcription factors, ArsR, LexA

\section{Introduction}

Microbes are highly adaptable to environmental toxic stress such as heavy metals, pesticides, and polychlorinated biphenyls (PCBs) (Chowdhury et al. 2018; Caine 2012). The adaptation to changes in their environment is controlled by the induction or repression of gene expression (Balleza et al. 2009; Cases et al. 2003). Association or dissociation of a transcription factor (TF) to its DNA

\footnotetext{
*Correspondence: jasonli@signosisinc.com; xumy@gdim.cn

${ }^{1}$ Guangdong Provincial Key Laboratory of Microbial Culture Collection and Application, State Key Laboratory of Applied Microbiology Southern China, Guangdong Institute of Microbiology, Guangdong Academy of Sciences, Guangzhou, China

Full list of author information is available at the end of the article
}

binding site is a critical step in the initiation of the transcription of its target gene (Fernandez-López et al. 2015; Rogers et al. 2015). It is vital to identify and characterize genes involved in the response to an environmental stress from the entire genome. This facilitates both the understanding of the mechanisms of gene regulation as well as the identification of the key regulatory elements during environmental adaptation in the host.

Environmental genomic toxic stresses such as certain types of chemical reagents and UV irradiation can cause changes in gene expression and cellular metabolism of microbe (Foster 2007). The distinguishing feature of these genes is the presence within the promoter region of a binding sequence for transcriptional repressors, such as LexA (Butala et al. 2009) and ArsR (Chen et al.
Springer Open (c) The Author(s) 2020. This article is licensed under a Creative Commons Attribution 4.0 International License, which permits use, sharing, adaptation, distribution and reproduction in any medium or format, as long as you give appropriate credit to the original author(s) and the source, provide a link to the Creative Commons licence, and indicate if changes were made. The images or other third party material in this article are included in the article's Creative Commons licence, unless indicated otherwise in a credit line to the material. If material is not included in the article's Creative Commons licence and your intended use is not permitted by statutory regulation or exceeds the permitted use, you will need to obtain permission directly from the copyright holder. To view a copy of this licence, visit http://creativeco mmons.org/licenses/by/4.0/. 
2017). LexA repressor normally is bound to its binding sites, repressing transcriptional expression. In response to any DNA damage, the LexA repressor undergoes dissociation from its binding sequences and activate DNA repair genes (Butala et al. 2009). ArsR is a regulatory protein that controls the expression of the genes involved in arsenical resistance via interaction with the arsenicresponsive operon (Wu and Rosen 1993). Upon arsenic binding, the protein dissociates from the promoter, subsequently activating relevant gene expression (Shi et al. 1994). Nevertheless, many toxic substances and their corresponding genes are not well characterized due to lack of simpler and more efficient methods.

Traditionally, transcription factor binding sites (TFBSs), are identified through approaches such as DNase I footprinting (Brenowitz et al. 1989) and electromobility shift assays (Hellman and Fried 2007), which are limited to the interactions between TFs and single targets. Recently, multiple TFs have been experimentally investigated using the systematic evolution of ligands by exponential enrichment (SELEX) (Ishihama et al. 2016) and chromatin immunoprecipitation with microarray (ChIP-chip) or by sequencing (ChIP-seq) (Galagan et al. 2013). Both ChIP-seq and genomic SELEX require the knowledge of stress-corresponding TFs prior to analysis, with time-consuming and tedious procedures. Recently many microbial genomes have been completely sequenced due to advances in the high-throughput genome sequencing, leading to computational methods to identify transcription factor binding sites (TFBSs) in these microbial genomes, However, computational method cannot identify the location and function of promoter region of a transcription factor (Inukai et al. 2017).

Identification of a specific target's responsive TFBS is very helpful for the development of bacteria biosensors in detecting a chemical substance and its toxicity. However, most of the current bacteria biosensors utilize the existing substrate-induced promoter and operator regions, such as arsenite detection biosensor with GFP (Zaslaver et al. 2006) and luciferase (Chen et al. 2019) as reporters. For a new and potential toxin without knowing its associated TFs, no global reporter method has been developed yet to identify and determine the associated TFs or TFBSs that are required in the regulation of gene expression.

In this study, we present an innovative high-throughput approach to screen and discover TFBSs in response to a stress substance directly without any prior genome information. Functional libraries have been constructed with enriched protein-bound genomic DNA fragments as enhancer and operators extracted from E. coli DH $5 \alpha$, along with downstream luciferase reporter to facilitate functional screening. $74 \%$ of the sequenced clones were predicted to contain regulatory TFBS with BPROM program from Softberry (Solovyev and Salamov 2011). From 80 randomly screened clones upon mitomycin C (MMC) treatment, two clones were found to be induced and confirmed to contain LexA binding sites. Furthermore, when screening another 90 clones with arsenite treatment, two clones were shown to be induced and have ArsR binding site, corresponding to arsR and osmE1. In the paper we newly discovered osmE1 gene, containing an ars $R$ binding motif. The gene expression of $o s m E 1$ was further validated by real-time RT-PCR in a dose-response and time course of arsenite-mediated induction.

\section{Materials and methods}

\section{Preparation of cell lysate proteins}

One $\mathrm{mL}$ of $E$. coli $\mathrm{DH} 5 \alpha$ culture was centrifuged at $10,000 \mathrm{~g}$ for $1 \mathrm{~min}$ and the pellet was resuspended in $300 \mu \mathrm{L}$ of lysis buffer $(10 \mathrm{mM}$ Tris $-\mathrm{HCl}, \mathrm{pH} 8.0,0.1 \mathrm{M}$ $\mathrm{NaCl}, 1 \mathrm{mM}$ ethylenediamine tetraacetic acid (EDTA), and $0.1 \%(\mathrm{w} / \mathrm{v})$ polyethylene glycol octylphenyl ether (Triton X-100)). $7.5 \mu \mathrm{L}$ of a freshly prepared lysozyme solution $(10 \mathrm{mg} / \mathrm{mL}$ in $10 \mathrm{mM}$ Tris- $\mathrm{HCl}, \mathrm{pH} 8.0$, final concentration $=0.25 \mathrm{mg} / \mathrm{mL}$ ) was added and mixed by tapping the tube gently, and the lysis mixture was incubated for 10-20 min at room temperature. After centrifugation, the supernatant was used for filter-binding selection.

\section{Preparation of Genomic DNA fragments}

DH5 $\alpha$ cells were collected through centrifugation, resuspended in $200 \mu \mathrm{L}$ lysis buffer $(10 \mathrm{mM}$ Tris- $\mathrm{HCl}, \mathrm{pH} 8.0$, $1 \mathrm{mM}$ EDTA, $0.5 \%$ SDS) and treated with $20 \mu \mathrm{g} / \mathrm{mL}$ proteinase $\mathrm{K}$ for $2 \mathrm{~h}$ at $55^{\circ} \mathrm{C}$. Genomic DNA was extracted with phenol and chloroform. The genomic DNA was digested with $M n l I, 5^{\prime} \ldots \mathrm{CCTC}(\mathrm{N}) 7 \ldots 3^{\prime}$, which recognizes four base pairs and generates one nucleotide protruding end at the $3^{\prime}$ terminus, for $1 \mathrm{~h}$ at $37^{\circ} \mathrm{C}$. The genomic DNA fragments were subsequently purified with MinElute Reaction Cleanup Kit (QIAGEN, Hilden, Germany).

\section{Filter-binding selection of protein-bound DNA fragments}

Five $\mu \mathrm{L}$ cell lysate $(2-10 \mu \mathrm{g})$ was mixed with $15 \mu \mathrm{L} 2 \mathrm{X}$ Binding buffer (40 mM 4-(2-hydroxyethyl)-1-piperazineethanesulfonic acid (HEPES), pH 7.6, $20 \mathrm{mM}$ ammonia sulfate, $2 \mathrm{mM}$ dithiothreitol (DTT), $20 \mathrm{mM} \mathrm{KCl}$, and $0.4 \%$ Tween-20), $M n l \mathrm{I}$-digested $5 \mu \mathrm{L}$ genomic DNA and

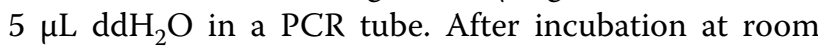
temperature for $30 \mathrm{~min}$, we loaded $30 \mu \mathrm{L}$ binding mixture onto a prewashed filter assay column and incubated on ice for $20 \mathrm{~min}$. The column is a nitrocellulose-based filter system, which can bind proteins and protein-DNA complex. After four times washing with Filter washing buffer to remove free DNA oligos, the bound DNA fragments 
were eluted with elution buffer (0.5\% SDS). The eluted DNA fragments were subsequently used for generating libraries.

\section{Construction of genomic libraries}

The eluted protein-bound DNA fragments were ligated with adaptors. MnlI digested fragments may have multiple nucleotide possibilities at the 3uterminus. Two basic sequences for making adaptors were selected to avoid cross hybridization with $E$. coli genome, $5^{\prime}$ ATGGATAGG TCGGTGA $3^{\prime}$ or $5^{\prime}$ GACGCACCTTGAGGC $3^{\prime}$. The double strand adaptors were designed and synthesized to match all possible fragments generated by MnlI-digestion (Fig. 1) and two DNA oligos were annealed to form the double strand adaptors with different protruding ends respectively. The oligos were designed and synthesized: (F1T 5'TCACCGACCTATCCAT-T3', F2T 5'GCC TCAAGGTGCGTC-T3', F1A 5'TCACCGACCTAT
CCAT-A3', F2A 5'GCCTCAAGGTGCGTC-A3', F1C 5'TCACCGACCTATCCAT-C3', F2C 5'GCCTCAAGG TGCGTC-C3', F1G 5'TCACCGACCTATCCAT-G3', and F2G $5^{\prime}$ GCCTCAAGGTGCGTC-G3'). F1 and F2 were annealed with R1S: 5'ATGGATAGGTCGGTGA3 ar R2S 5'GACGCACCTTGAGGC3' accordingly to form eight adaptors: 5AA, 5AG, 5AC, 5AT, 3AA, 3AG, 3AC, and 3AT (Table 1). After ligation of adaptors with DNA fragments, 16 combinations were amplified by 10 PCR cycles with a forward primer introduced with $\mathrm{XbaI}$ sequence and a reverse primer with HindIII sequence. The amplified products were digested with $\mathrm{XbaI}$ and HindIII and cloned into pACYC-Luc vector, which was modified in our previous publication (Chen et al. 2019), originally derived from pACYC184 (New England Biolabs, Ipswich, MA, USA) to generate 16 libraries (AA, AT, AC, AG; TA, TT, TC, TG; CA, CT, CC, CG; GA, GT, GC, GG) listed

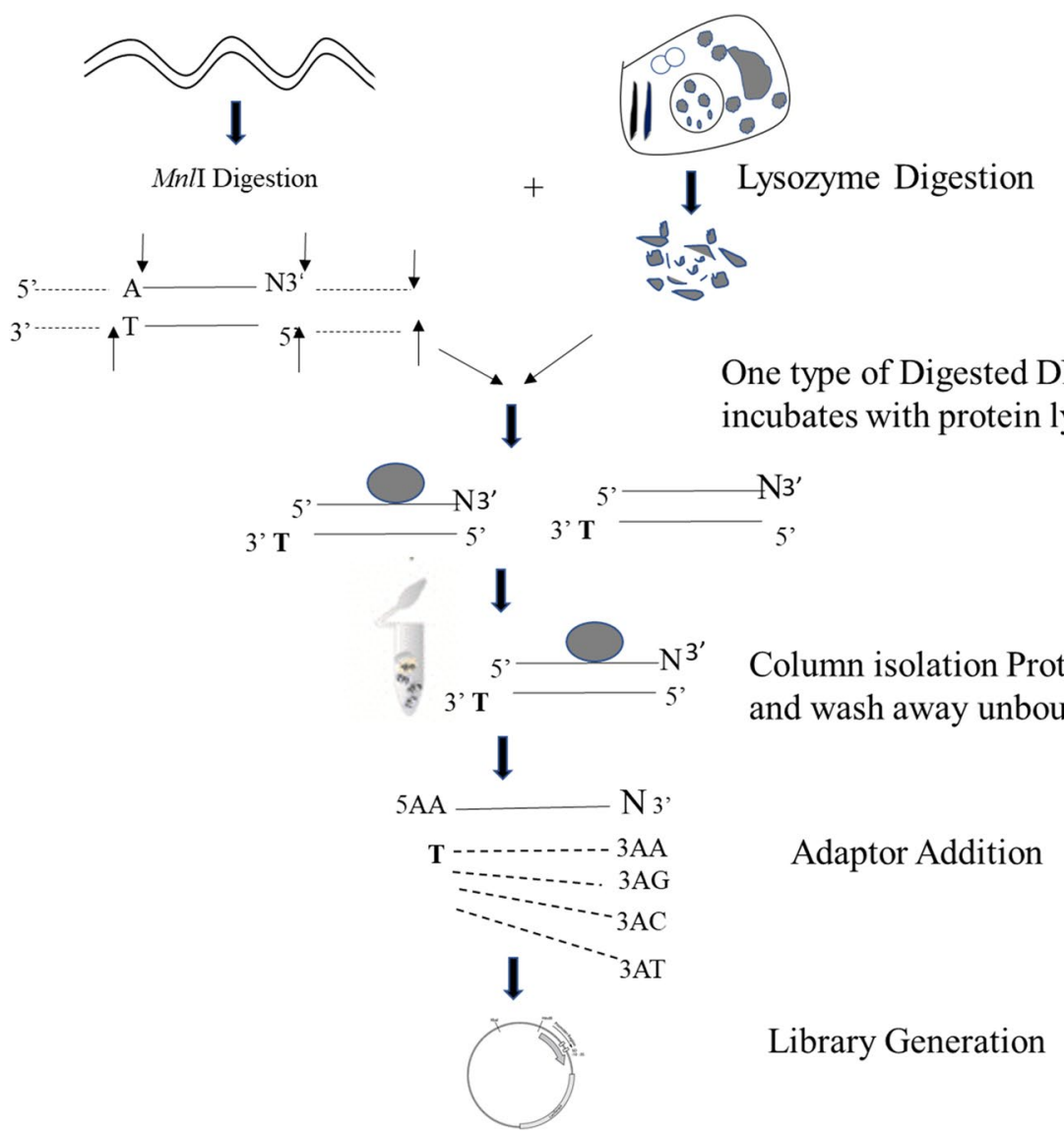

Fig. 1 a Schematic diagram of separation of protein-binding genomic DNA fragments for library construction. Genomic DNA was prepared from DH5a with proteinase K digestion followed by phenol and chloroform extraction. It was then sheared with Mnll digestion. Proteins were also extracted from DH5a cells and incubated with the genomic DNA fragments to allow formation of protein/DNA complexes, which were able to retain on a filter column and to separate from the unbound DNA by the following washing steps. The protein-bound DNA fragments were then eluted and used for construction of libraries. b 8 different adaptors were made, AA5, AG5, AC5, and AT5, for ligating to $5^{\prime}$ end of Mn/l fragments, and $A A 3, A G 3, A C 3$, and AT3 for ligation to $3^{\prime}$ terminus of Mnll fragments 
Table 1 Sixteen genome libraries generated from combination of eight adaptors sequences randomly digested by $\mathrm{Mn} / \mathrm{l}$ restriction enzyme

\begin{tabular}{|c|c|c|c|c|c|c|}
\hline No & $\begin{array}{l}\text { Genome } \\
\text { library names }\end{array}$ & $\begin{array}{l}\text { Adaptor } \\
\text { combination }^{\mathrm{a}}\end{array}$ & $\begin{array}{l}\text { 5'Adaptor } \\
\text { name }\end{array}$ & 5' Adaptor sequence & $\begin{array}{l}3^{\prime} \text { Adaptor } \\
\text { name }\end{array}$ & $3^{\prime}$ Adaptor sequence \\
\hline 1 & AA & 5AA-3AA & $5 A A$ & $\begin{array}{l}5^{\prime} \text { ATGGATAGGTCGGTGA } 3^{\prime}(\mathrm{R} 1 \mathrm{~S}) \\
\text { 3'A-TACCTATCCAGCCACT 5' }^{\prime} \text { (F1A) }\end{array}$ & $3 A A$ & $\begin{array}{l}5^{\prime} \text { GACGCACCTTGAGGC 3' (R2S) } \\
\text { 3'A-CTGCGTGGAACTCCG 5' (F2A) }\end{array}$ \\
\hline 2 & AT & 5AA-3AT & & & उAT & $\begin{array}{l}\text { 5' GACGCACCTTGAGGC 3' (R2S) } \\
\text { 3'T-CTGCGTGGAACTCCG 5' (F2T) }\end{array}$ \\
\hline 3 & $A G$ & $5 A A-3 A G$ & & & $3 A G$ & $\begin{array}{l}\text { 5' GACGCACCTTGAGGC 3' (R2S) } \\
\text { 3'G-CTGCGTGGAACTCCG 5' (F2G) }\end{array}$ \\
\hline 4 & $A C$ & 5AA-3AC & & & $3 A C$ & $\begin{array}{l}5^{\prime} \text { GACGCACCTTGAGGC 3' (R2S) } \\
\text { 3'C-CTGCGTGGAACTCCG 5' (F2C) }\end{array}$ \\
\hline 5 & TA & 5TA-3AA & 5TA & 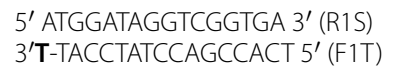 & $3 A A$ & 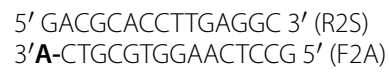 \\
\hline 6 & TT & 5TA-3AT & & & उAT & $\begin{array}{l}\text { 5' GACGCACCTTGAGGC 3' (R2S) } \\
\text { 3'T-CTGCGTGGAACTCCG 5' (F2T) }\end{array}$ \\
\hline 7 & $\mathrm{TG}$ & 5TA-3AG & & & $3 A G$ & $\begin{array}{l}\text { 5' GACGCACCTTGAGGC 3' (R2S) } \\
\text { 3'G-CTGCGTGGAACTCCG 5' (F2G) }\end{array}$ \\
\hline 8 & TC & 5TA-3AC & & & $3 A C$ & $\begin{array}{l}\text { 5' GACGCACCTTGAGGC 3' (R2S) } \\
\text { 3'C-CTGCGTGGAACTCCG 5' (F2C) }\end{array}$ \\
\hline 9 & GA & 5GA-3AA & $5 G A$ & $\begin{array}{l}5^{\prime} \text { ATGGATAGGTCGGTGA } 3^{\prime} \text { (R1S) } \\
\text { 3'G-TACCTATCCAGCCACT 5' (F1G) }\end{array}$ & $3 \mathrm{AA}$ & $\begin{array}{l}\text { 5' GACGCACCTTGAGGC 3' (R2S) } \\
\text { 3'A-CTGCGTGGAACTCCG 5' (F2A) }\end{array}$ \\
\hline 10 & GT & 5GA-3AT & & & उAT & $\begin{array}{l}\text { 5'GACGCACCTTGAGGC 3' (R2S) } \\
\text { 3'T-CTGCGTGGAACTCCG 5' (F2T) }\end{array}$ \\
\hline 11 & GG & $5 G A-3 A G$ & & & $3 A G$ & $\begin{array}{l}\text { 5' GACGCACCTTGAGGC 3' (R2S) } \\
\text { 3'G-CTGCGTGGAACTCCG 5' (F2G) }\end{array}$ \\
\hline 12 & GC & $5 G A-3 A C$ & & & $3 A C$ & 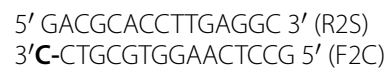 \\
\hline 13 & CA & 5CA-3AA & $5 C A$ & $\begin{array}{l}\text { 5' ATGGATAGGTCGGTGA 3' (R1S) } \\
3^{\prime} \mathbf{C} \text {-TACCTATCCAGCCACT 5' (F1C) }\end{array}$ & $3 \mathrm{AA}$ & $\begin{array}{l}\text { 5' GACGCACCTTGAGGC 3' (R2S) } \\
\text { 3'A-CTGCGTGGAACTCCG 5' (F2A) }\end{array}$ \\
\hline 14 & $C T$ & $5 C A-3 A T$ & & & उAT & $\begin{array}{l}\text { 5' GACGCACCTTGAGGC 3' (R2S) } \\
\text { 3'T-CTGCGTGGAACTCCG 5' (F2T) }\end{array}$ \\
\hline 15 & CG & $5 C A-3 A G$ & & & $3 A G$ & $\begin{array}{l}\text { 5' GACGCACCTTGAGGC 3' (R2S) } \\
\text { 3'G-CTGCGTGGAACTCCG 5' (F2G) }\end{array}$ \\
\hline 16 & CC & $5 C A-3 A C$ & & & $3 A C$ & $\begin{array}{l}5^{\prime} \text { GACGCACCTTGAGGC 3' (R2S) } \\
\text { 3'C-CTGCGTGGAACTCCG 5' (F2C) }\end{array}$ \\
\hline
\end{tabular}

a Each adaptor was abbreviated with 5AA (5' adaptor A), 5AT (5' adaptor T), 5AG ( $3^{\prime}$ adaptor $\left.\mathrm{G}\right)$, etc. $5^{\prime}$ adaptors are annealed with shared sequence R1S while $3^{\prime}$ adaptors were annealed with sharded sequence R2S. Each $5^{\prime}$ adaptor was combined with each $3^{\prime}$ adaptor to create a total of 16 genome libraries

in Table 1. After transformation, the clones (colonies) were selected on ampicillin plates, and plasmid DNAs from 280 clones were subsequently either prepared and sequenced, or directly conducted induction luciferase screening assay.

\section{Luciferase assay}

For the screening assay, 80-90 individual colonies were picked and inoculated in $600 \mu \mathrm{L} \mathrm{LB}$ media supplied with $25 \mu \mathrm{g} / \mathrm{mL}$ chloramphenicol, and incubated for $12-16 \mathrm{~h}$ at $37^{\circ} \mathrm{C}$ in the corresponding wells of 96 well deep plate with vigorous shaking. The overnight culture was diluted 1:50 in a new 96 well deep plate with pre-warm and freshprepared $600 \mu \mathrm{L}$ LB media supplied with chloramphenicol. The diluted cells were cultured for an additional $4 \mathrm{~h}$ at $37{ }^{\circ} \mathrm{C}$ until the optical density (O.D.) reached 0.5. Cells were treated with or without $\mathrm{MMC}$, or sodium arsenite
(AsIII) at $37^{\circ} \mathrm{C} .20 \mu \mathrm{L}$ of induced culture was mixed with $50 \mu \mathrm{L}$ luciferase substrate, and the luciferase activity was measured with Veritas Microplate Luminometer (Tuner Biosystems, Sunnyvale, CA, USA). For an individual clone assay, a plasmid was transformed into $\mathrm{DH} 5 \alpha$, and a single colony was inoculated in $2 \mathrm{~mL} \mathrm{LB}$ media $25 \mu \mathrm{g} /$ $\mathrm{mL}$ chloramphenicol for $12-16 \mathrm{~h}$ at $37{ }^{\circ} \mathrm{C}$ in an individual tube, with the rest of steps being the same as the screening assay and treatment following the description in the results.

\section{Real-time RT-PCR}

A single DH5 $\alpha$ colony with the OsmE1 promoter containing clone was cultured overnight and diluted at 1:50 with LB before with MMC treatment in a time course and dose response manner (the detail see in result). Total RNA was prepared with Monarch Total RNA Miniprep 
Kit (New England Biolabs, Ipswich, MA, USA) with DNAase treatment to remove residual DNA. Integrity of RNA was assessed by electrophoresis. RNA concentration was determined with Qubit ${ }^{\mathrm{TM}}$ RNA BR Assay Kit (Thermo Fisher Scientific, Waltham, MA, USA) in Qubit 2.0 Fluorometer according to manufacturer's instructions. Extracted RNA (400 ng) was reverse transcribed to cDNA with AMV Reverse Transcriptase (Life Science Advanced Technology, St Petersburg, FL, USA). The primers for the target gene OsmE1 and three reference genes were designed with vector NTI (Thermo Fisher Scientific, Waltham, MA, USA) and using Primer-BLAST (NCBI, USA) and synthesized at IDT (Integrated DNA Technologies, Coralville, IA, USA). The primer specificity was confirmed by $2 \%$ agarose gel electrophoresis.

SYBR green-based real-time PCR was performed with ABI PRISM 7000 sequence detection system. $20 \mu \mathrm{L}$ of PCR reaction was prepared based on Q5 DNA polymerase system (New England Biolabs, Ipswich, MA, USA) with 1X SYBR Green, 1X ROX dye (Roche, Basel, Switzerland), $1 \mu \mathrm{M}$ forward and reverse primer. The amount of cDNA used in each qPCR reaction was: $1 \mu \mathrm{L}$ for target gene osmE1, $1 \mu \mathrm{L}$ for reference genes, gry $\mathrm{A}$ and $\mathrm{mGOD}$, and $0.6 \mu \mathrm{L}$ of 1:100 diluted cDNA for 16S rRNA. These were pre-determined by testing serial dilutions of cDNA samples to achieve the threshold cycle $(\mathrm{Ct})$ values of the three reference genes similar to that of the target gene. We ran the PCR reaction at $50{ }^{\circ} \mathrm{C}$ for $2 \mathrm{~min}$ and $98{ }^{\circ} \mathrm{C}$ for $5 \mathrm{~min}$, followed by 40 cycles at $98{ }^{\circ} \mathrm{C}$ for $15 \mathrm{~s}, 55^{\circ} \mathrm{C}$ for $30 \mathrm{~s}$, and $72{ }^{\circ} \mathrm{C}$ for $30 \mathrm{~s}$. A dissociation stage was then performed as follows: $95^{\circ} \mathrm{C}$ for $15 \mathrm{~s}, 60^{\circ} \mathrm{C}$ for $20 \mathrm{~s}$, and $95{ }^{\circ} \mathrm{C}$ for $15 \mathrm{~s}$. All samples were run in duplicate, and the mean $\mathrm{Ct}$ values for each trial were calculated. $\Delta \mathrm{Ct}$ was then calculated as the difference between target gene and the geometric mean of three reference genes. $\Delta \Delta \mathrm{Ct}$ was obtained by normalizing the $\Delta \mathrm{Ct}$ values of the treatments to the $\Delta \mathrm{Ct}$ value of the control without treatment. Finally, relative target gene expression values were calculated with $2^{-\Delta \Delta C t}$ (Livak and Schmittgen 2001).

\section{Results}

This screening libraries consist of enriching proteinbound genomic DNA fragments and downstream luciferase reporters. The DNA fragments were generated based on the protein/DNA complex formation and protein/DNA complex separation (Fig. 1). To construct these libraries, E. coli genomic DNA was digested with a restriction enzyme $M n l$ I that recognizes non-palindromic nucleotide sequence 5n/DNA comple (Kriukiene et al. 2005), each fragment with one protruding nucleotide at 3cleot with four possibilities: A G, C, and $\mathrm{T}$. If there were DNA fragments containing promoters or TFBS and their corresponding DNA binding proteins in DH5 $\alpha$ lysates such as Sigma 70 or TFs, protein/DNA complexes were formed. The enriched protein-bound DNA fragments were obtained and utilized to generate 16 libraries to contain all of promoter and operator regions of genomic DNA. Additionally, these libraries also are functional libraries with luciferase reporter gene. Once the TFs bind on the regulatory DNA regions of libraries, release repressor, and initiate the transcription of luciferase gene. Through measurement of luciferase activities, the clones containing regulatory DNA in response to a treatment.

In order to evaluate libraries with useful TFBS information, approximately 560 clones were obtained from the transformation of these libraries. Of these clones, we selected 280 for sequencing and generated 178 sequences with promoter region sizes around 70-300 bp. First, we analyzed these sequences with a computational analysis of promoter regions and TFBSs. Prokaryotic transcription is performed by RNA polymerase that contains four catalytic subunits and a sigma regulatory subunit. Seven total distinct sigma factors bind a set of promoter sequences and different sigma factors binding sites. The conservative sequences can be found between -10 base pairs and - 35 base pairs upstream of the transcription start site in the promoter regions and TFBSs where located upstream of the promoter region acting as an enhancer or a repressor. Using the computer program BPROM (Solovyev and Salamov 2011), we found only 54 sequences having a-10 and -35 bp sigma factor. 71 have at least one TFBS and sigma factors and 6 only contain TFBS without sigma factor. A total of 131 out of 178 clones contain either promoter sequences or TFBSs, or both (shown in Table 2). The sequencing analysis showed that some promoter sequences displayed multiple TFBSs, such as $e l b B$ containing RpoD18, LexA, GLP, ArcA, FimZ and $\operatorname{ArgR}$, while some had only one TFBS such as $d t p D$ containing only LexA. This study revealed a total of 35 unique TFs. Each TF was predicted by BPROM based on its consensus binding element, but the binding sequence on a specific promoter region may be different, which is the reason why we obtained much more the binding sequences than the number of unique TFs (Table 3).

In order to conduct functionality of the predicted TFBS in reporter vector, we first chose lexA as our testing target since the LexA DNA binding site was recognized to appear more frequently than others, and was predicted to be located on several gene promoter sequences, including $k d o$, fimZ, $d t p D$, and ElbB. Furthermore, LexA is widely studied and is well known to be induced by environmental stress (Maslowska et al. 2019; Kreuzer 2013). Five clones containing LexA binding sites were selected for functional tests of MMC-mediated activation of LexA: clone $137 d t p D$, clone 138 elbB, clone 152 
Table 2 List of clones containing with -35 and -10 conservative sequences or TF binding sequences

\begin{tabular}{|c|c|c|c|c|c|}
\hline Gene names & Clone ID & Library & Encoded function & $\begin{array}{l}\text { Insert } \\
\text { length } \\
\text { (bp) }\end{array}$ & TFBS \\
\hline aor & 141 & $\mathrm{TC}$ & $\begin{array}{l}\text { Aldehyde ferredoxin oxidore- } \\
\text { ductase }\end{array}$ & 279 & Sigma70 \\
\hline $\mathrm{araH}$ & 28 & GA & $\begin{array}{l}\text { L-arabinose } A B C \text { transporter } \\
\text { permease }\end{array}$ & 167 & Sigma70, DnaA \\
\hline $\operatorname{arcB}$ & 47 & $A C$ & Sensor histidine kinase & 258 & Sigma 70, Ihf \\
\hline $\arg B$ & 80 & $A C$ & Acetylglutamate kinase & 225 & Sigma70, ArgR2, Ihf \\
\hline $\operatorname{ars} B$ & $65,85,108,114$ & $\mathrm{AG}, \mathrm{CA} C \mathrm{~T}, \mathrm{TT}$ & $\begin{array}{l}\text { Arsenite/antimonite:H(+) } \\
\text { antiporter }\end{array}$ & 320 & Sigma70 \\
\hline bglH & 72 & AT & $\begin{array}{l}\text { Carbohydrate-specific outer } \\
\text { membrane porin }\end{array}$ & 244 & Sigma70, PurR \\
\hline$b s / 78$ & 107 & $\mathrm{CT}$ & $\begin{array}{l}\text { DNA (cytosine-5-)-methyltrans- } \\
\text { ferase }\end{array}$ & 218 & Sigma 70 \\
\hline casle & 18 & GG & $\begin{array}{l}\text { Type I-E CRISPR-associated } \\
\text { protein }\end{array}$ & 186 & Sigma70, RpoS17 \\
\hline $\operatorname{cas} A$ & 37 & GG & CRISPR system Cascade subunit & 158 & Sigma70, RpoS17 \\
\hline$c h b c$ & 73 & AT & $\begin{array}{l}\text { N,N'-diacetylchitobiose-specific } \\
\text { PTS enzyme IIC }\end{array}$ & 158 & Fur, RpoD17 \\
\hline$c h b G$ & 70,91 & AT & Chitin disaccharide deacetylase & 157 & Sigma70 \\
\hline clk_1237 & 177 & TA & $\begin{array}{l}\text { ADP-ribosylglycohydrolase fam- } \\
\text { ily protein }\end{array}$ & 124 & Sigma70 \\
\hline$c t k$ & 93 & CA & $\begin{array}{l}\text { DUF4297 domain-containing } \\
\text { protein }\end{array}$ & 135 & Sigma70, RpoD15, metJ \\
\hline сtpA3 & 144 & $\mathrm{TC}$ & $\begin{array}{l}\text { Carboxyl-terminal-processing } \\
\text { peptidase } 3 \text {, chloroplastic }\end{array}$ & 158 & Sigma70 \\
\hline$c y d D$ & 145 & $\mathrm{TC}$ & $\begin{array}{l}\text { Cysteine/glutathione ABC trans- } \\
\text { porter permease/ATP-binding } \\
\text { protein }\end{array}$ & 167 & Sigma70 \\
\hline$d g c$ & 122 & $\mathrm{TT}$ & Diguanylate cyclases & 105 & Sigma70, RpoD17 \\
\hline$d t p D$ & 137 & TC & Dipeptide permease & 213 & Sigma70, LexA \\
\hline eamA & 74 & AT & $\begin{array}{l}\text { Cysteine/O-acetylserine } \\
\text { exporter EamA }\end{array}$ & 184 & Sigma70 \\
\hline ecm18 & 150 & $\mathrm{TG}$ & $\begin{array}{l}\text { Class I SAM-dependent methyl- } \\
\text { transferase }\end{array}$ & 270 & Sigma70, Crp, SoxS \\
\hline ef2563 & 35 & GG & $\begin{array}{l}\text { Selenium-dependent molyb- } \\
\text { denum hydroxylase system } \\
\text { protein }\end{array}$ & 133 & Sigma70 \\
\hline egc82 & 33 & GG & $\begin{array}{l}\text { D-hexose-6-phosphate mutaro- } \\
\text { tase }\end{array}$ & 139 & Sigma70 \\
\hline$e l b B$ & 138 & TC & $\begin{array}{l}\text { Isoprenoid biosynthesis gly- } \\
\text { oxalase }\end{array}$ & 328 & $\begin{array}{l}\text { Sigma70, Irp,RpoH2, LexA, ArcA, } \\
\text { argR, GlpR: }\end{array}$ \\
\hline fof1 & 171 & TA & ATP synthase subunit delta & 134 & Sigma70 \\
\hline fimZ & 165 & TA & $\begin{array}{l}\text { Fimbriae biosynthesis transcrip- } \\
\text { tional regulator }\end{array}$ & 96 & Sigma70, PurR, LexA1, LexA2, PurR \\
\hline frdA & 117 & $\mathrm{TT}$ & $\begin{array}{l}\text { Fumarate reductase flavoprotein } \\
\text { subunit }\end{array}$ & 357 & Sigma70 \\
\hline frs $A$ & 1,81 & $\mathrm{GA}, \mathrm{AC}$ & Esterase & 193 & Sigma70 \\
\hline ftrl & $\begin{array}{l}3,4,11,12,13,14,15,21,27 \\
57,62,95,97,110,111,112 \\
126,154\end{array}$ & $\begin{array}{l}\mathrm{GA}, \mathrm{GC}, \mathrm{GT}, \mathrm{AC} \\
\mathrm{AG}, \mathrm{CG}, \mathrm{CT} \\
\mathrm{TC}, \mathrm{TG}\end{array}$ & Iron permease & 145 & Sigma70, RpoD16, MetJ \\
\hline gaf & 6,24 & $\mathrm{GA}, \mathrm{TC}$ & GAF domain-containing protein & 262 & Ihf \\
\hline gltT & 86 & CA & $\begin{array}{l}\text { Cation:dicarboxylase symporter } \\
\text { familytransporter }\end{array}$ & 263 & Sigma70, RpoD17, OmpR \\
\hline $\operatorname{gsh} B$ & 59 & $A G$ & Glutathione synthase & 208 & Sigma70, Fis \\
\hline
\end{tabular}


Table 2 (continued)

\begin{tabular}{|c|c|c|c|c|c|}
\hline Gene names & Clone ID & Library & Encoded function & $\begin{array}{l}\text { Insert } \\
\text { length } \\
\text { (bp) }\end{array}$ & TFBS \\
\hline hcaE & 30 & GA & $\begin{array}{l}\text { 3-Phenylpropionate/cinnamic } \\
\text { acid dioxygenase subunit } \\
\text { alpha }\end{array}$ & 140 & Sigma70, DnaA \\
\hline hemk & 147 & $\mathrm{TC}$ & $\begin{array}{l}\text { Peptide chain release factor } \\
\text { N(5)-glutamate }\end{array}$ & 366 & Sigma70 \\
\hline$h f l C$ & 63 & $A G$ & Protease modulator & 320 & Sigma 70 \\
\hline hipA & 42 & $\mathrm{AA}$ & $\begin{array}{l}\text { Type II toxin-antitoxin system } \\
\text { serine/threonine protein } \\
\text { kinase toxin }\end{array}$ & 230 & Sigma70, RpoD17 \\
\hline hjr & 22 & GG & Holliday junction resolvase & 432 & RpoD17 \\
\hline$h s d R$ & 157 & $\mathrm{TG}$ & $\begin{array}{l}\text { Type I restriction-modification } \\
\text { system endonuclease }\end{array}$ & 278 & Sigma70 \\
\hline ICSA & 153 & $\mathrm{TG}$ & $\begin{array}{l}\text { Outer membrane protein IcsA } \\
\text { autotransporter precursor }\end{array}$ & 196 & Sigma70, RpoD17, SoxS \\
\hline$\| A$ & 55 & $A C$ & $\begin{array}{l}\text { PTS mannitol transporter } \\
\text { subunit }\end{array}$ & 154 & Sigma70, Ihf. ArgR2, RpoD17 \\
\hline kch & 53 & $A C$ & $\begin{array}{l}\text { Voltage-gated potassium } \\
\text { channel }\end{array}$ & 160 & Sigma70, MetJ, RpoH2 \\
\hline$k d o$ & 170 & TA & $\begin{array}{l}\text { 3-Deoxy-manno-octulosonate } \\
\text { cytidylyltransferase }\end{array}$ & 119 & Sigma70, LexA, RpoD18, PurR \\
\hline kup & 155 & $\mathrm{TG}$ & $\begin{array}{l}\text { Low affinity potassium trans- } \\
\text { porte }\end{array}$ & 154 & Sigma70 \\
\hline IpfC & 136,178 & $\mathrm{TC}, \mathrm{TA}$ & $\begin{array}{l}\text { Fimbrial biogenesis outer mem- } \\
\text { brane usher protein }\end{array}$ & 155 & Sigma70 \\
\hline maaFP003_1916 & 31 & GA & $\begin{array}{l}\text { Si-specific NAD(P) (+) transhy- } \\
\text { drogenase }\end{array}$ & 381 & Sigma70 \\
\hline maeB & 94,116 & $\mathrm{CA}, \mathrm{TT}$ & $\begin{array}{l}\text { NADP-dependent oxaloacetate- } \\
\text { decarboxylating malate } \\
\text { dehydrogenase }\end{array}$ & 121 & Sigma, RpoD17, ArgR \\
\hline$m c r B$ & 39 & GG & $\begin{array}{l}\text { 5-Methylcytosine-specific } \\
\text { restriction enzyme B }\end{array}$ & 128 & Sigma70, RpoD17, Irp, Fnr, NagC \\
\hline$m h p R$ & 127 & $\mathrm{TC}$ & $\begin{array}{l}\text { DNA-binding transcriptional } \\
\text { activator }\end{array}$ & 284 & Sigma70, RpoD17, ArgR, ArcA \\
\hline$m n m C$ & 69 & AT & $\begin{array}{l}\text { 5-Methylaminomethyl-2-thiouri- } \\
\text { dine biosynthesis bifunctional } \\
\text { protein }\end{array}$ & 182 & Sigma70 \\
\hline motA & 9 & GC & Flagellar motor stator protein 98 & 98 & FliA, MotAB, CheAW, CpxR \\
\hline msyB & 120 & $\mathrm{TT}$ & Acidic protein & 308 & Sigma70, SoxS \\
\hline mukF & 20 & GG & Chromosome partition protein & 123 & $\begin{array}{l}\text { Sigma70, RpoD17, Irp, RpoH2, Fnr, } \\
\text { NagC }\end{array}$ \\
\hline narG & 159 & TG & Nitrate reductase subunit alpha & 154 & Sigma70, ArgR \\
\hline narl & 10 & GC & $\begin{array}{l}\text { Respiratory nitrate reductase } \\
\text { subunit gamma } 195\end{array}$ & 195 & Sigma70, Crp \\
\hline nikC & 45 & $\mathrm{AA}$ & $\begin{array}{l}\text { Nickel ABC transporter per- } \\
\text { mease subunit }\end{array}$ & 164 & Sigma70, RpoD16 \\
\hline$n r d D$ & 175 & TA & $\begin{array}{l}\text { Anaerobic ribonucleoside- } \\
\text { triphosphate reductase }\end{array}$ & 350 & Sigma70 \\
\hline nuoE & 158 & TG & $\begin{array}{l}\text { NADH-quinone oxidoreductase } \\
\text { subunit NuoE }\end{array}$ & 222 & Sigma70, Crp \\
\hline pntA & 8,50 & GA & $\begin{array}{l}\text { Si-specific NAD }(P) \text { transhydro- } \\
\text { genase }\end{array}$ & 415 & Sigma70 \\
\hline rase & 56 & $A C$ & $\begin{array}{l}\text { 4-Hydroxybenzoate octaprenyl- } \\
\text { transfe }\end{array}$ & 178 & Sigma, PurR \\
\hline rayt & 88 & CA & $\begin{array}{l}\text { REP-associated tyrosine trans- } \\
\text { posase }\end{array}$ & 248 & Sigma70 \\
\hline
\end{tabular}


Table 2 (continued)

\begin{tabular}{|c|c|c|c|c|c|}
\hline Gene names & Clone ID & Library & Encoded function & $\begin{array}{l}\text { Insert } \\
\text { length } \\
\text { (bp) }\end{array}$ & TFBS \\
\hline rep & 139 & $\mathrm{TC}$ & $\begin{array}{l}\text { ATP-dependent DNA helicase } \\
\text { Rep }\end{array}$ & 185 & Sigma70 \\
\hline rpos & 156 & TG & RNA polymerase sigma factor & 315 & Sigma70, Crp \\
\hline rppH & 169 & TA & RNA pyrophosphohydrolase & 396 & Sigma70, NarP \\
\hline$r r l$ & 61 & $A G$ & $23 \mathrm{~S}$ ribosomal RNA & 153 & Crp, RpoD15 \\
\hline $\operatorname{san} A$ & 67 & AT & $\begin{array}{l}\text { Outer membrane permeability } \\
\text { protein }\end{array}$ & 193 & Sigma 70 \\
\hline$s d r$ & 149 & $\mathrm{TG}$ & Short-chain dehydrogenase & 99 & Sigma70 \\
\hline $\sec A$ & 167 & TA & $\begin{array}{l}\text { Preprotein translocase subunit } \\
\text { SecA }\end{array}$ & 161 & Sigma70, RpoD17, Ihf \\
\hline sgr & 132 & TC & $\begin{array}{l}\text { Helix-turn-helix domain-con- } \\
\text { taining protein }\end{array}$ & 199 & Sigma70, ArgR2 \\
\hline speF & 90 & $C A$ & Ornithine decarboxylase SpeF & 128 & Sigma70 \\
\hline spy & 105 & $\mathrm{CT}$ & $\begin{array}{l}\text { ATP-independent periplasmic } \\
\text { protein-refolding chaperone }\end{array}$ & 233 & Ihf, Fis, Irp, \\
\hline $\operatorname{tes} B$ & 173 & TA & Acyl-CoA thioesterase II & 133 & Sigma70, RpoD16 \\
\hline thip & 99 & CT & $\begin{array}{l}\text { Thiamine/thiamine pyroph- } \\
\text { osphate ABC transporter } \\
\text { permease }\end{array}$ & 210 & Sigma70, OmpR \\
\hline tolc & 115 & $\mathrm{TT}$ & $\begin{array}{l}\text { Outer membrane channel } \\
\text { protein }\end{array}$ & 128 & $\operatorname{ArgR}$ \\
\hline $\operatorname{trpS} / p g p$ & 123 & $\mathrm{TT}$ & $\begin{array}{l}\text { Tryptophan-tRNA ligase Phos- } \\
\text { phoglycolate phosphatase }\end{array}$ & 115 & Sigma70 \\
\hline tyrR & 134 & $\mathrm{TC}$ & Transcriptional regulator & 147 & $\begin{array}{l}\text { RpoD19, RpoD17, Crp, OmpR, } \\
\text { MetR }\end{array}$ \\
\hline ucpA & 100 & $\mathrm{CT}$ & SDR family oxidoreductase & 133 & Sigma70, Fnr \\
\hline ugdH & 121 & $\mathrm{TT}$ & UDP-glucose 6-dehydrogenase & 294 & $\begin{array}{l}\text { Sigma70, FlhCD, RpoH2, RpoD17, } \\
\text { Fnr, Irp }\end{array}$ \\
\hline uhpC & 16 & GG & $\begin{array}{l}\text { MFS transporter family glucose- } \\
\text { 6-phosphate receptor }\end{array}$ & 174 & Sigma70, ArgR \\
\hline$w b b l$ & 5,29 & GA & $\begin{array}{l}\text { Beta-1,6-galactofuranosyltrans- } \\
\text { ferase }\end{array}$ & 200 & Sigma70 \\
\hline wcal & 129 & TC & $\begin{array}{l}\text { Colanic acid biosynthesis glyco- } \\
\text { syltransferase }\end{array}$ & 290 & Sigma70 \\
\hline weel & 24,75 & GT & $\begin{array}{l}\text { Beta-1,6-galactofuranosyltrans- } \\
\text { ferase }\end{array}$ & 217 & $\begin{array}{l}\text { Sigma70, RpoD17, } \\
\text { RpoD16,RpoD17,RpoD17 }\end{array}$ \\
\hline$w Z C$ & 109 & CT & Tyrosine-protein kinase & 179 & Sigma70 \\
\hline ybat & 89 & CA & Amino acid permease & 171 & $\operatorname{ArgR2}$, Ihf, ArcA \\
\hline ybjx & 49 & $A C$ & $\begin{array}{l}\text { DUF535 domain-containing } \\
\text { protein YbjX }\end{array}$ & 145 & Sigma70 \\
\hline$y c b V$ & 148 & $\mathrm{TG}$ & $\begin{array}{l}\text { Putative fimbrial-like adhesin } \\
\text { protein }\end{array}$ & 110 & $\begin{array}{l}\text { Sigma70, Crp, RpoD15, PhoB, } \\
\text { RpoD17, Irp }\end{array}$ \\
\hline ychE & 131 & TC & NAAT family transporter & 258 & $\begin{array}{l}\text { Sigma70, RpoD16, Irp, SoxS, TyrR, } \\
\text { GlpR, RpoD18 }\end{array}$ \\
\hline$y d h W$ & $23,25,40$ & GT & Oxidoreductase & 183 & Sigma70 \\
\hline ydiv & 52 & $A C$ & $\begin{array}{l}\text { EAL domain-containing protein } \\
\text { bacteria }\end{array}$ & 241 & Sigma70, Crp \\
\hline yeaw & 101 & CT & $\begin{array}{l}\text { Carnitine monooxygenase } \\
\text { subunit }\end{array}$ & 179 & Sigma 70 \\
\hline yedE/fdhT & 48 & $A C$ & $\begin{array}{l}\text { Selenium metabolism mem- } \\
\text { brane protein }\end{array}$ & 110 & Sigma70 \\
\hline yeel & 119 & $\mathrm{TT}$ & Inverse autotransporter adhesin & 182 & Sigma70 \\
\hline yeiH & 135 & $\mathrm{TC}$ & $\begin{array}{l}\text { YeiH family putative sulfate } \\
\text { export transporter }\end{array}$ & 114 & $\begin{array}{l}\text { Sigma70, OxyR, arcA, Fnr, RpoD18, } \\
\text { TyrR, Fnr, DeoR, Ihf, ArgR2 }\end{array}$ \\
\hline
\end{tabular}


Table 2 (continued)

\begin{tabular}{|c|c|c|c|c|c|}
\hline Gene names & Clone ID & Library & Encoded function & $\begin{array}{l}\text { Insert } \\
\text { length } \\
\text { (bp) }\end{array}$ & TFBS \\
\hline yfex & 54 & $A C$ & Porphyrinogen peroxidase & 167 & Sigma70 \\
\hline yhdP & 46 & $\mathrm{AA}$ & $\begin{array}{l}\text { AsmA2 domain-containing } \\
\text { protein }\end{array}$ & 200 & Sigma70 \\
\hline yidR & 125 & TC & $\begin{array}{l}\text { DUF3748 domain-containing } \\
\text { galacturonate catabolism } \\
\text { protein }\end{array}$ & 174 & Sigma70 \\
\hline yihG & 151 & TG & Putative acyltransferase & 186 & Sigma70 \\
\hline yneE & 98 & CG & $\begin{array}{l}\text { Bestrophin family inner mem- } \\
\text { brane protein }\end{array}$ & 120 & Sigma70 \\
\hline \multirow[t]{4}{*}{ ypfG } & 64 & $A G$ & $\begin{array}{l}\text { DUF1176 domain-containing } \\
\text { protein }\end{array}$ & 328 & Sigma70, RpoH3 \\
\hline & 26 & GT & Hypothetical protein & 211 & Sigma 70, ArgR2, Crp \\
\hline & 152 & $\mathrm{TG}$ & Non-coding, Pseudo genes & 186 & Sigma70, Fis, Fnr, LexA \\
\hline & 161 & $\mathrm{TG}$ & Unknown & 626 & Sigma70 \\
\hline
\end{tabular}

(non-coding Pseudo gene), clone 170 kdo and clone 165 fim $Z$, which was previously reported to be regulated by LexA (Saini et al. 2009). These clone plasmids were transformed into DH5a, and inoculated and treated with 0, 0.2 and $0.5 \mu \mathrm{M} \mathrm{MMC}$ for 2,4 and 16 h respectively (Fig. 2), and cell lysates were prepared for luciferase analysis. $2 \mathrm{~h}$ treatment did not show significant induction rate (Fig. 2a). Even though all of these clones showed the clear induction at $0.5 \mu \mathrm{g} / \mathrm{mL} \mathrm{MMC} \mathrm{for} 4 \mathrm{~h}$ treatment (Fig. 2b), the induction patterns showed a slight difference in terms of the condition for highest induction: clone 137 and clone 165 showed highest induction at $0.2 \mu \mathrm{g} / \mathrm{mL}$ for a $16 \mathrm{~h}$ treatment (Fig. 2c), while clone 138, clone 152 and clone 170 showed highest induction at $0.5 \mu \mathrm{g} / \mathrm{mL}$ for $4 \mathrm{~h}$ treatment (Fig. 2b). The results of the clones containing LexA binding sequences were confirmed to be induced by MMC with luciferase assays, since the LexA binding sequences in these clones come from different gene promoter regions, which may affect the responding pattern of MMC treatment.

To further demonstrate the feasibility of direct library screening without prior information, 80 clones were randomly selected from libraries. We chose treatment conditions of $0.5 \mu \mathrm{g} / \mathrm{mL}$ for $4 \mathrm{~h}$ since under these conditions all of the LexA binding site containing clones showed a significant induction. Cell lysates were prepared and subjected to luciferase analysis. As shown in Fig. 3a, 80 clones were first screened with MMC treatment, and 6 clones with higher luciferase activities (>550 RLU (relative light unit)) were selected for induction assay. Two clones, clone 56 and clone 71, were identified with twofold LexA induction (Fig. 3b). Sequencing analysis with BLAST search (NCBI, USA) revealed that clone 56 is an unknown target, and clone 71 contains elbB. Both clones were further analyzed with BPROM and predicted with a LexA binding site. The predicted LexA binding sequence in clone 71 is TTTTTTTA; while clone 138 is TAAATT ATTAT.

To validate our direct screening function of libraries, we utilized $\operatorname{ars} R$ as another screening target, which we have widely studied in our recent publication (Chen et al. 2019). Another 90 clones from libraries were cultured and treated with $5 \mu \mathrm{M}$ arsenite for $2 \mathrm{~h}$ based our previous optimal conditions. Nine clones showing high luciferase activities (>600 RLU) (Fig. 4a) were then selected and analyzed thoroughly with individual arsenite induction assay. Two clones, clone 12 and 68, were confirmed to have greater than twofolds induction. The plasmids were prepared from clone 12 and 68 and then subjected to sequencing. Through NCBI BLAST search, clone 12 revealed osmE1 and clone 68 revealed arsR. Both clones were unable to be analyzed with the promoter prediction program BPROM as the program does not contain ArsR binding sequences, although Arsenite-mediated induction of ArsR is well-documented (Chen et al. 2017, 2019; Bose et al. 2006; Kostal et al. 2004). The arsR binding site on ArsR found in this study TTAAATCATATGCGTTTT TGGTT was the identical to the published one (Xu et al. 1996). The potential ArsR binding site on osmE1 were predicted to be GCtTGAAAAAGCGCCCAaTG based on reported consensus sequence, tTGxxxx xx xxxxCAa (Busenlehner et al. 2003) shown in Fig. 5.

Since $o s m E 1$ is not well studied and is newly discovered in our study, this gene induction by arsenite treatment needs to be further investigated. To analyze arsenite-mediated induction of $o s m E 1$ gene expression, 
Table 3 All 35 predicted TFBS with regulation of downstream genes

\begin{tabular}{|c|c|c|}
\hline Number & TFBS & Corresponding genes \\
\hline 1 & RpoD16 & ftr1, weel, nikC, narl, ychE, tesB \\
\hline 2 & MetJ & $f t r 1, k c h, c t k$ \\
\hline 3 & Ihf & gaf, arcB, IIA, argB, ybaT, spy, yeiH, secA \\
\hline 4 & FliA & motA \\
\hline 5 & MotAB-CheAW & motA \\
\hline 6 & CpxR & $m o t A, f t r 1$ \\
\hline 7 & Crp & narl, ydiV, rrl, tyrR, ycbV, ecm 18, rpos, nuoE \\
\hline 8 & $\operatorname{ArgR}$ & uhpC, maeB, tolC, $m h p R$, elbB, narG, \\
\hline 9 & Rpos17 & casle, $\operatorname{cas} A$ \\
\hline 10 & RpoD17 & $\begin{array}{l}\text { hjr, mukF, weel, mcrB, hipA, IIA, chbC, gltT, maeB, } \\
\text { etc. }\end{array}$ \\
\hline 11 & Lrp & mukF, spy, ugdH, ychE, elbB, ycbV \\
\hline 12 & $\mathrm{RpoH} 2$ & mukF, kch, ugdH, elbB, \\
\hline 13 & Fnr & mukF, mcrB, ucpA, ugdH, yeiH \\
\hline 14 & NagC & mukF, mcrB \\
\hline 15 & ArgR2 & $\| A, \arg B, y b a T$, ftrl, sgr, yeiH \\
\hline 16 & DnaA & araH, hcaE \\
\hline 17 & Fis & gshB, spy, \\
\hline 18 & RpoD15 & $r r l, c t k, f t r 1, y c b V$ \\
\hline 19 & $\mathrm{RpoH} 3$ & $y p f G$ \\
\hline 20 & PurR & rase, bglH, fimZ, kdo \\
\hline 21 & SoxS & narl, msyB, ychE, ecm 18, IcsA \\
\hline 22 & OmpR & gltT, thiP, ftr1, tyrR \\
\hline 23 & ArcA & $m h p R$, yeiH, elbB, ybaT, \\
\hline 24 & FlhCD & ugdH \\
\hline 25 & TyrR & ychE, yeiH \\
\hline 26 & GlpR & $y c h E, e l b B$ \\
\hline 27 & RpoD18 & ychE, yeiH, kdo \\
\hline 28 & MetR & tyrR \\
\hline 29 & OxyR & yeiH \\
\hline 30 & DeoR & yeiH \\
\hline 31 & LexA & $d t p D$, elbB, fimZ, kdo, pseuo \\
\hline 32 & PhoB & $y c b V$ \\
\hline 33 & LexA1 & $f i m Z$ \\
\hline 34 & LexA2 & fimZ \\
\hline 35 & NarP & rpph \\
\hline
\end{tabular}

we utilized real time RT-PCR quantitative measurement in time and dose course. For dose response assays, DH $5 \alpha$ cells were treated with $0,0.04,0.08 .0 .16,0.31,0.63,1.25$, $2.5,5$, and $10 \mu \mathrm{M}$ arsenite for $2 \mathrm{~h}$. Total RNAs were prepared, and reverse transcribed to cDNA. SYBR Green PCR reactions were performed in duplicate, and the mean $\mathrm{Ct}$ values for each trial were calculated. As shown in Fig. 6a, the treatment with $2.5 \mu \mathrm{M}$ of arsenite yielded the highest induction of osmE1 gene expression. Next, we examined the time-course response of $O s m E 1$ gene expression to $2.5 \mu \mathrm{M}$ arsenite for periods of $0,15,30,60$

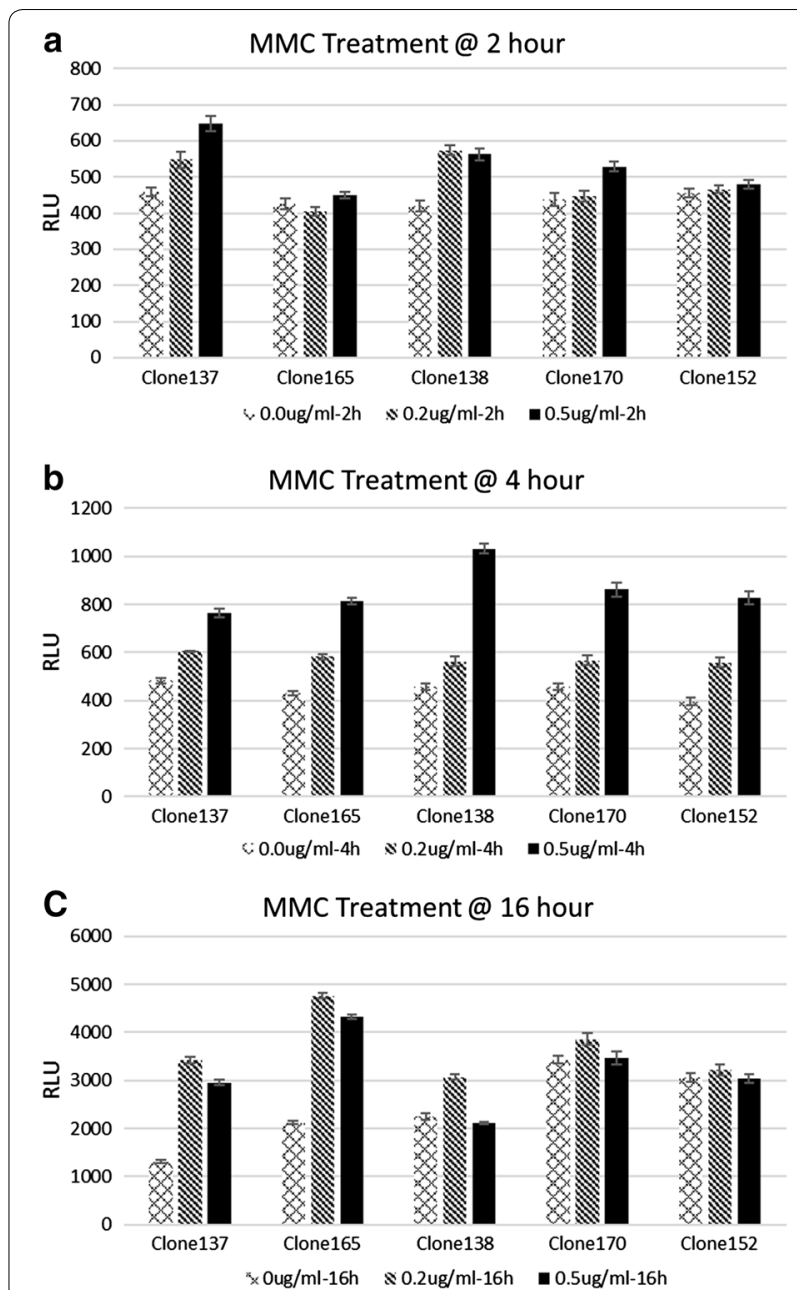

Fig. 2 Analysis of LexA-containing clones in response to mitomycin $C$ treatment. From protein-bound genomic DNA fragment libraries, five clones containing LexA binding sequences were identified through sequencing and TFBS motif search. These clones were selected and treated with $0,0.2$ and $0.5 \mu \mathrm{M}$ mitomycin C for 2 (a), 4 (b), and $16 \mathrm{~h}$ (c) respectively. Cells were collected for luciferase analysis

and $120 \mathrm{~min}$. The samples were collected at the indicated time points and quantification of osmE1 gene expression normalized using the references. The results revealed that the 120 min treatment yielded the highest induction, ninefolds, of osmE1 gene expression (Fig. 6b).

\section{Discussion}

Bacteria biosensors act as a new class of detectors to produce a detectable signal upon activation of a promoter reporter gene induced by specific stimuli, which have been used for monitoring environmental pollutants such as heavy metals or pesticides (Gutiérrez et al. 2015). The key component of whole-cell biosensors is 


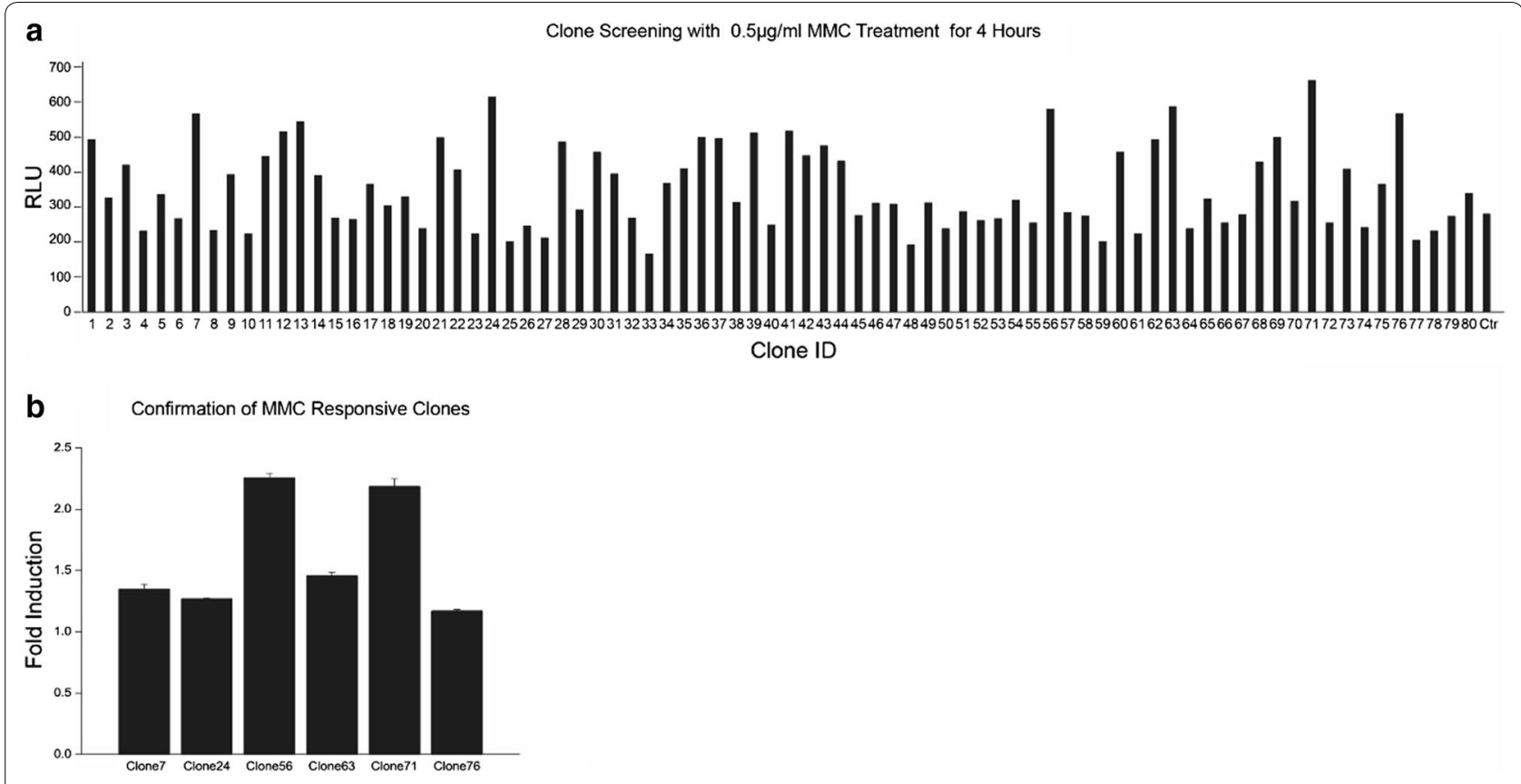

Fig. 3 Directly functional screening of mitomycin C-responsive clones. Eighty clones randomly selected from generated library, cultured them with $0.5 \mu \mathrm{M}$ mitomycin $\mathrm{C}$ treatment for $4 \mathrm{~h}$, and subject to luciferase analysis (a). Six clones with luciferase activities $>550$ RLU were selected for induction assay with and without mitomycin $C$ treatment (b)

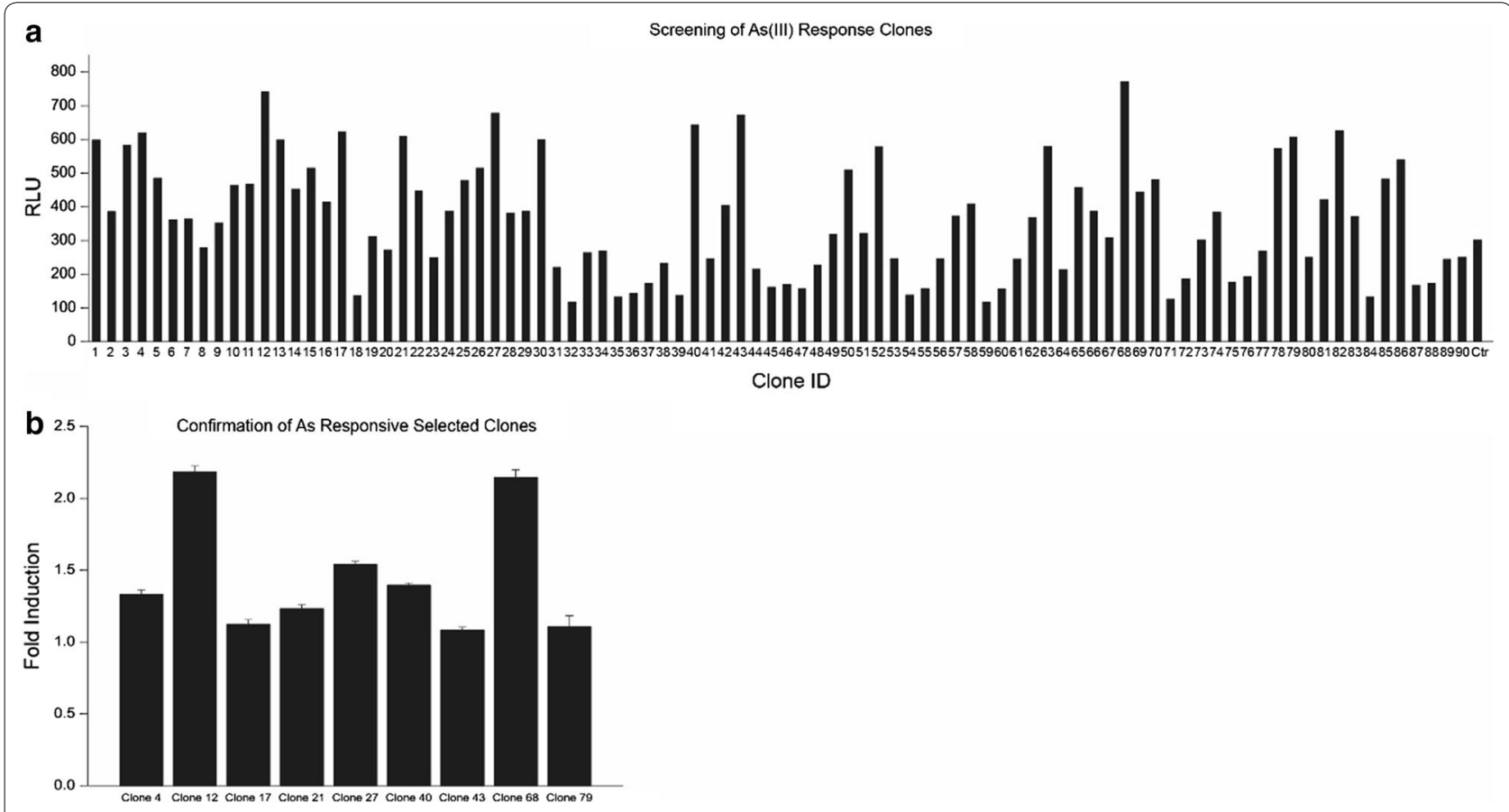

Fig. 4 Directly functional screening of arsenite-responsive clones. Ninety clones from library were randomly selected, cultured with $5 \mu \mathrm{M}$ arsenite treatment for 2 h, and subject to luciferase analysis (a). Nine clones with luciferase activities $>600$ RLU were then selected for arsenite induction assay (b) 


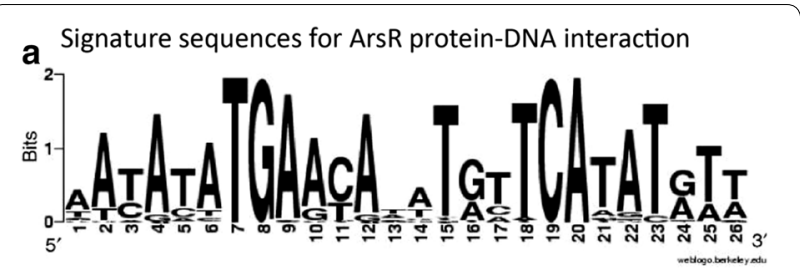

b ArsR potential site on OsmE1 promoter region GgGctTGaAaAagcGccCAatg

Fig. 5 Signature sequences for ars $R$ protein-DNA interaction and OsmE1 promoter region

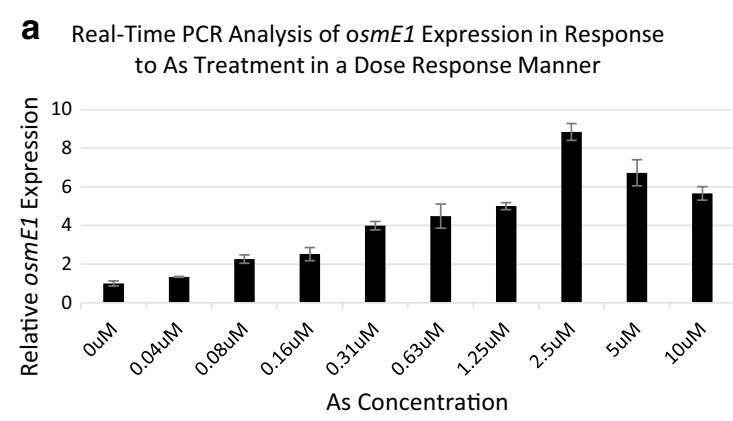

b Real-time PCR Analysis osmE1 Expression in Response to As

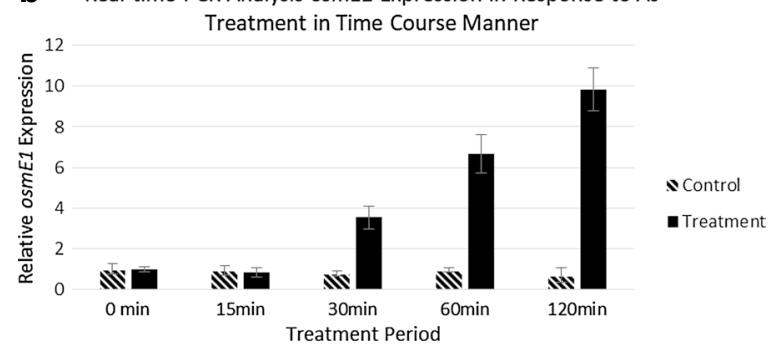

Fig. 6 Quantitative analysis of osmE1 gene expression with RT-PCR. DH5a were treated with $0,0.04,0.08,0.16,0.31,0.63,1.25,2.5,5$, and $10 \mu \mathrm{M}$ arsenite for $2 \mathrm{~h}(\mathbf{a})$ or with $2.5 \mu \mathrm{M}$ arsensite for $0,15,30,60$, and $120 \mathrm{~min}$ (b). RNA was isolated from DH5a and reverse transcribed to CDNA with AMV. Real-time PCR with SYBR green was performed with ABI PRISM 7000 Sequence Detection System. Quantification of osmE1 RNA was normalized using reference 16S rRNA, gryA and mGOD

the reporter (Gui et al. 2017), consisting of a promoter/ operator and a reporter gene. Therefore, it is crucial to find a responding promoter/operator in a high throughput method from surviving microbes in an environment containing a target pollutant. The current bacteria reporter biosensors are only for the known toxin substance-induced TFBS constructed reporter system, and cannot be used for discovering a TF and the associated TFBS for a novel substance.
This study presents a novel approach to enriching protein-bound genomic DNA fragments for the construction of luciferase libraries conducting directly functional screening to identify substance-responsive TFBS elements. This dramatically reduces time and labor in the screening of unknown TFBS elements in response to a potential toxin substance. It has been widely known that there are around $300 \mathrm{TFs}$ and seven sigma factors in the E. coli genome (Pérez-Rueda and Collado-Vides 2000; Tripathi et al. 2014). Our protein bound enriched DNA libraries displayed 131 TFBS containing clones from screening 280 clones based on sequencing analysis and bacteria TFBS prediction software BPROM, and identified two well-studied ArsR (Chen et al. 2017, 2019; Bose et al. 2006; Kostal et al. 2004) and FimZ (Saini et al. 2009) among these TFs, which demonstrating our libraries are highly enriched with useful TFBS information. In addition, through luciferase assay, the same TF (such as LexA) on the promoter region with different binding sequences were shown to have various induction patterns, therefore the libraries can not only obtain a specific TF binding motif, but also provide multiple promoter associated binding sequences with different induction patterns, which may offer possibilities to develop more sensitive and selective stress substance screening system. Through direct functional screening, we were able to obtain MMC-responsive lexA clones and As-responsive arsR and osmE1 clones. These results showed that our functional libraries can be utilized to efficiently screen and discover the responsive clones under stress substance stimulation. Our library screening does not require the prior knowledge of the target microbial genome or any known transcription factor, therefore our libraries have great potential to be used for identifying a specific TF binding site of a given substance, and developing functional screening methods for unknown microbes with very limited physiological and genomic information.

Studies demonstrate that arsenite can mediate ArsR induction, which is well-documented in literature (Chen et al. 2017, 2019; Bose et al. 2006; Kostal et al. 2004). ArsR, belonging to the Smt/ArsR family, is a regulatory protein that controls the expression of the genes involved in arsenical resistance via interaction with the arsenicresponsive operon (Chen et al. 2017). Due to the abundant presence of ArsR binding sequences in microbial chromosomes, the alignment of these binding sequences via comparison and analysis leads to the identification of a binding consensus sequence (Saini et al. 2009). SmtB/ ArsR binding sequences share a conserved 12-2-12 palindrome (Kostal et al. 2004). Our recent study indicated that among the inverted repeat, TC and GA are critical to ArsR binding (Chen et al. 2019). Interestingly, we found that OsmE1 is also a target capable of regulation 
by arsenite, although this has been shown in only one previous study (Patel 2005). This study reported that the Identification of the arsenic binding-protein fractions with arsenic analysis revealed two low molecular weight proteins, which one of them being OsmE1. Cells under arsenate stress conditions could allow the expression of osmE1. Further studies need to determine how many genes are induced under arsenic stress, how they are regulated by arsenite, and what function they play in response to arsenic stress.

Our E. coli protein-bound DNA enriched functional library technology can easily be adapted to mammalian TFBS identification; however, mammalian transcriptional regulation is much more complicated than bacteria transcriptional regulation as there are more than 2000 TFs for mammals (Brivanlou and Darnell 2002). Luciferasebased screening may be time-consuming to assay individual clones. GFP reporter can replace luciferase reporter to construct libraries, so that the differentially expressed reporter genes can be easily identified through fluorescence-activated cell sorting (FACS) to sort the interesting population in response to a certain treatment. Our protein-bound enriched functional library technology has a wide application for TFBS identification of unknown transcriptional regulation in prokaryotic and eukaryotic system.

\section{Acknowledgements}

Not applicable.

\section{Authors' contributions}

$X L$ contributed to experimental design. $X J$ performed clone library screening $M Y$, YF, and YW contributed to data analysis. XL, MY, GS, and JG were involved with study design and overseeing the experiments. The manuscript was written by $\mathrm{XL}$, and all authors commented on the manuscript. All authors read and approved the final manuscript.

\section{Funding}

This work was supported by the High-level Leading Talent Introduction Program of GDAS (2016GDASRC-0208) and the Science and Technology Planning Project of Guangzhou City (201707020021) to XL, National Natural Science Foundation of China (91851202) and the Science and Technology Project of Guangdong Province (2019B110205004) to MX.

\section{Availability of data and materials}

All data and materials are available.

\section{Ethics approval and consent to participate}

This article does not contain any studies with human participants and animals performed by any of the authors.

\section{Consent for publication}

All authors consent the publication.

\section{Competing interests}

The authors declare that they have no conflict of interest.

\section{Author details}

${ }^{1}$ Guangdong Provincial Key Laboratory of Microbial Culture Collection and Application, State Key Laboratory of Applied Microbiology Southern China, Guangdong Institute of Microbiology, Guangdong Academy of Sciences, Guangzhou, China. ${ }^{2}$ Science and Technology Library of Guangdong
Province and Guangdong Institute of Science and Technology Information and Development Strategy, Guangzhou, China.

Received: 10 October 2020 Accepted: 18 October 2020

Published online: 02 November 2020

\section{References}

Balleza E, Lopez-Bojorquez LN, Martínez-Antonio A, Resendis-Antonio O, Lozada-Chávez I, Balderas-Martínez YI, Encarnación S, Collado-Vides J (2009) Regulation by transcription factors in bacteria: beyond description. FEMS Microbiol Rev 33:133-151

Bose M, Slick D, Sarto MJ, Murphy P, Roberts D, Roberts J, Barber RD (2006) Identification of SmtB/ArsR cis elements and proteins in archaea using the Prokaryotic InterGenic Exploration Database (PIGED). Archaea 2(39-49):22

Brenowitz M, Senear DF, Kingston RE (1989) DNase I footprint analysis of protein-DNA binding. Curr Protoc Mol Biol 7:12-14

Brivanlou AH, Darnell JE Jr (2002) Signal transduction and the control of gene expression. Science 295:813-881

Busenlehner LS, Pennella MA, Giedroc DP (2003) The SmtB/ArsR family of metalloregulatory transcriptional repressors: structural insights into prokaryotic metal resistance. FEMS Microbiol Rev 27:131-143

Butala M, Žgur-Bertok D, Busby SJ (2009) The bacterial LexA transcriptional repressor. Cell Mol Life Sci 66:82

Caine ED (2012) Health risks from toxic pollution. Lancet 380:1532

Cases I, De Lorenzo V, Ouzounis CA (2003) Transcription regulation and environmental adaptation in bacteria. Trends Microbiol 11:248-253

Chen J, Nadar VS, Rosen BP (2017) A novel MAs(III)-selective ArsR transcriptional repressor. Mol Microbiol 106:469-478

Chen X, Jiang X, Tie C, Yoo J, Wang Y, Xu M, Sun G, Guo J, Li X (2019) Contribution of nonconsensus base pairs within ArsR binding sequences toward ArsR-DNA binding and arsenic-mediated transcriptional induction. J Biol Eng 13:53-64

Chowdhury R, Ramond A, O'Keeffe LM, Shahzad S, Kunutsor SK, Muka T, Gregson J, Willeit P, Warnakula S, Khan H, Chowdhury S, Gobin R, Franco $\mathrm{OH}$, Di Angelantonio E (2018) Environmental toxic metal contaminants and risk of cardiovascular disease: systematic review and meta-analysis. BMJ 362:k3310

Fernandez-López R, Ruiz R, de la Cruz F, Moncalián G (2015) Transcription factor-based biosensors enlightened by the analyte. Front Microbiol 6:648

Foster PL (2007) Stress-induced mutagenesis in bacteria. Crit Rev Biochem Mol Biol 42:373-397

Galagan J, Lyubetskaya A, Gomes A (2013) ChIP-Seq and the complexity of bacterial transcriptional regulation. Curr Top Microbiol Immunol 363:43-68

Gui Q, Lawson T, Shan S, Yan L, Liu Y (2017) The application of whole cell-based biosensors for use in environmental analysis and in medical diagnostics. Sensors 17:1623

Gutiérrez JC, Amaro F, Martín-González A (2015) Heavy metal whole-cell biosensors using eukaryotic microorganisms: an updated critical review. Front Microbiol 6:48

Hellman LM, Fried MG (2007) Electrophoretic mobility shift assay (EMSA) for detecting protein-nucleic acid interactions. Nat Protoc 2:1849

Inukai S, Kock KH, Bulyk ML (2017) Transcription factor-DNA binding: beyond binding site motifs. Curr Opin Genet Dev 43:110-119

Ishihama A, Shimada T, Yamazaki Y (2016) Transcription profile of Escherichia coli: genomic SELEX search for regulatory targets of transcription factors. Nucleic Acids Res 44:2058-2074

Kostal J, Yang R, Wu CH, Mulchandani A, Chen W (2004) Enhanced arsenic accumulation in engineered bacterial cells expressing ArsR. Appl Environ Microbiol 70:4582-4587

Kreuzer KN (2013) DNA damage responses in prokaryotes: regulating gene expression, modulating growth patterns, and manipulating replication forks. Cold Spring Harb Perspect Biol 5:a012674

Kriukiene E, Lubiene J, Lagunavicius A, Lubys A (2005) Mnll-The member of $\mathrm{H}-\mathrm{N}-\mathrm{H}$ subtype of Type IIS restriction endonucleases. Biochim Biophys Acta 1751:194-204 
Livak KJ, Schmittgen TD (2001) Analysis of relative gene expression data using real-time quantitative PCR and the 2(-Delta Delta C(T)) Method. Methods 25:402-408

Maslowska KH, Makiela-Dzbenska K, Fijalkowska IJ (2019) The SOS system: a complex and tightly regulated response to DNA damage. Environ Mol Mutagen 60:368-384

Patel PC (2005) Molecular and biochemical characterization of arsenic resistance in pseudomonas species. Sardar Patel University, Anand

Pérez-Rueda E, Collado-Vides J (2000) The repertoire of DNA-binding transcriptional regulators in Escherichia coli K-12. Nucleic Acids Res 28:1838-1847

Rogers JK, Guzman CD, Taylor ND, Raman S, Anderson K, Church GM (2015)

Synthetic biosensors for precise gene control and real-time monitoring of metabolites. Nucleic Acids Res 43:7648-7660

Saini S, Pearl JA, Rao CV (2009) Role of FimW, FimY, and FimZ in regulating the expression of type i fimbriae in Salmonella enterica serovar Typhimurium.J Bacteriol 191:3003-3010

Shi W, Wu J, Rosen BP (1994) Identification of a putative metal binding site in a new family of metalloregulatory proteins. J Biol Chem 269:19826-19829

Solovyev V, Salamov A (2011) Automatic annotation of microbial genomes and metagenomic sequences. In: Li RW (ed) Metagenomics and its applications in agriculture, biomedicine and environmental studies. Nova Science Publishers, Hauppauge

Tripathi L, Zhang Y, Lin Z (2014) Bacterial sigma factors as targets for engineered or synthetic transcriptional control. Front Bioeng Biotechnol 2:33

Wu J, Rosen BP (1993) Metalloregulated expression of the ars operon. J Biol Chem 268:52-58

Xu C, Shi W, Rosen BP (1996) The chromosomal arsR gene of Escherichia coli encodes a trans-acting metalloregulatory protein. J Biol Chem 271:2427-2432

Zaslaver A, Bren A, Ronen M, Itzkovitz S, Kikoin I, Shavit S, Liebermeister W, Surette MG, Alon U (2006) A comprehensive library of fluorescent transcriptional reporters for Escherichia coli. Nat Methods 3:623-628

\section{Publisher's Note}

Springer Nature remains neutral with regard to jurisdictional claims in published maps and institutional affiliations.

\section{Submit your manuscript to a SpringerOpen ${ }^{\circ}$ journal and benefit from:}

- Convenient online submission

- Rigorous peer review

- Open access: articles freely available online

- High visibility within the field

- Retaining the copyright to your article

Submit your next manuscript at $\boldsymbol{\nabla}$ springeropen.com 